\title{
Effect of Sympathetic ganglionectomy on the Pineal Gland in Rhesus Monkey
}

\author{
V. Bharihoke \\ Professor and Head of Department of Anatomy. University College of medical Sciences and GTB Hospital \\ Delhi 110095 India
}

\begin{abstract}
The light microscopic structure and the effect of superior cervical ganglionectomy on the pineal gland of Rhesus monkey was studied in 24 animals. The animals were divided into three groups. Group I normal controls, Group II after unilateral and Group III after bilateral ganglionectomy. The animals in group II were sacrificed 15 days and group III were sacrificed 21 days after the operation. Every seventh slide of serial paraffin sections were stained with $H \& E$ stain, Red Holzer's stain for glial fibers, Weigert's and Van Gieson's stain, Weil's stain for myelin sheath, Peter's protein silver stain for nerve fibers and Glee's stain for degenerating nerve fibers.

A close relationship between the processes of the pinealocytes and interstitial cells and capillaries was suggestive of an exchange of material between the two types of cells and blood vessels. Two types of acervulei in the control group, type I comprising of concentric whorl around a central heterochromatic nucleus and the type II made up of superimposed droplets were noted in the control group. Degenerating nerve fibers, cell free areas and acervulei of superimposed secretions were seen in group II and III suggesting an autonomic nervous control on the secretions of the gland.
\end{abstract}

\section{Introduction:}

The pineal gland, in the ancient times was called the "seat of the soul" [1] and "the mystical third eye of man" by the Hindus. In the modern days Arien Kappers [2] called it a "regulator of regulators" as it inhibits the secretions of the hypophysis cerebri. Now it has been found to be an endocrine gland which secretes melatonin. It develops from the neuroepithelium and receives nerve fibers from the hypothalamus via the superior cervical sympathetic ganglion [3, 4]. sphenopalatine ganglia [ 5], trigeminal ganglion and habenular complex[6]. The exact mode of secretion in the gland is still not clear. The pineal gland also contains neurons and/or neuron-like peptidergic cells in higher vertebrates. The peptidergic cells are believed to influence the pinealocytes by paracrine secretion of the peptides [7]. The parasympathetic nerve fibers contain vasoactive intestinal peptide and peptide histidine isoleucine which are known for their vasodilator role and their influence on the light dark cycle in rats [7]

Most functions of the nervous tissue are deduced by the presence of the various neurotransmitters in the gland and demonstration of numerous receptors on the cell membrane, which are able to bind the neurotransmitters locating on the pineal petal nerve fibers [4]. Thus the mammalian pinealocyte can be influenced by a plethora of neurotransmitters $[3,4,5$, and 6]. There is a species variation in the structure and function of the gland [8]. Most studies have been conducted on small animals. Although the presence of neurotransmitters has become a guide to the probable functions in the nervous system, most inferences are broadly based on hypothesis. Out of the various neuroanatomical techniques the effect of denervation has been found to elucidate the function of the organ. This study focuses on the effect of removal of sympathetic nerves on the pineal gland of monkey as it forms a major source of innervations to the gland. There is a dearth of literature on this aspect on large animals.

\section{Material And Methods:}

24 monkeys (mисаса mulata) weighing between $4.5-8.5 \mathrm{Kg}$ of either sex were used in the study. The animals were divided into Group I: normal controls, Group II: unilateral superior cervical ganglionectomy was done, Group III: bilateral superior cervical ganglionectomy was done. Superior cervical ganglionectomy was performed after anaesthetizing the animal with intraperitoneal injection of thiopentone sodium $35 \mathrm{mg} / \mathrm{Kg}$ body weight in water. Animals in Group II were sacrificed on the 15th and group III on 21st postoperative day. The success of the operation was ascertained by ptosis in the animal postoperatively. Animals were perfused with $10 \%$ formal saline. All procedures were performed under thiopentone anaesthesia and full care was taken so that the animals were pain free. All procedures confirmed with the rules laid down by the 'society of prevention of cruelty to animals'.

Pineal glands were removed and embedded in paraffin. $7 \mu$ serial sections were cut and mounted on glass slides. Every seventh slide was stained with one of the following stains: H\&E stain. Red Holzer's stain for 
glial fibers, Weigert's and Van Gieson's stain, Weil's stain for myelin sheath, Peter's protein silver stain for nerve fibers and Glee's stain for degenerating nerve fibers. The slides were examined under a light microscope.

\section{Results:}

The gland was covered by a connective tissue capsule. It was divided into lobules by septa. Nerve fibers were seen entering the gland at the apex as well as all along the capsule. The parenchyma was filled with pinealocytes with large nuclei and the nuclear membrane was thrown into folds (Fig 1) and spindle shaped darkly staining cells called interstial cells which showed affinity towards glial stains.

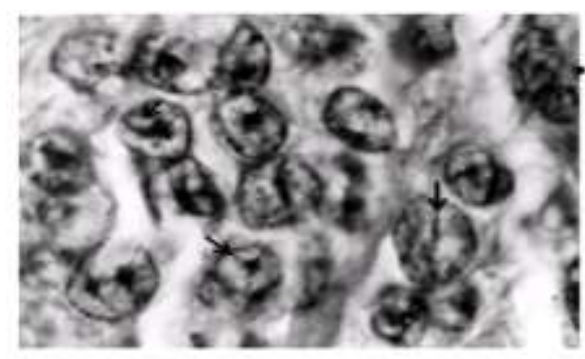

Fig.1. Collections of pinealocytes in the pineal gland. Note the folds in the nucleus (arrows). Weigert's Van Gieson's stain X 2000

The pinealocytes were found making contact with the darkly stained cells with elongated nuclei typical or interstitial cells (Fig. 2 \& 3).
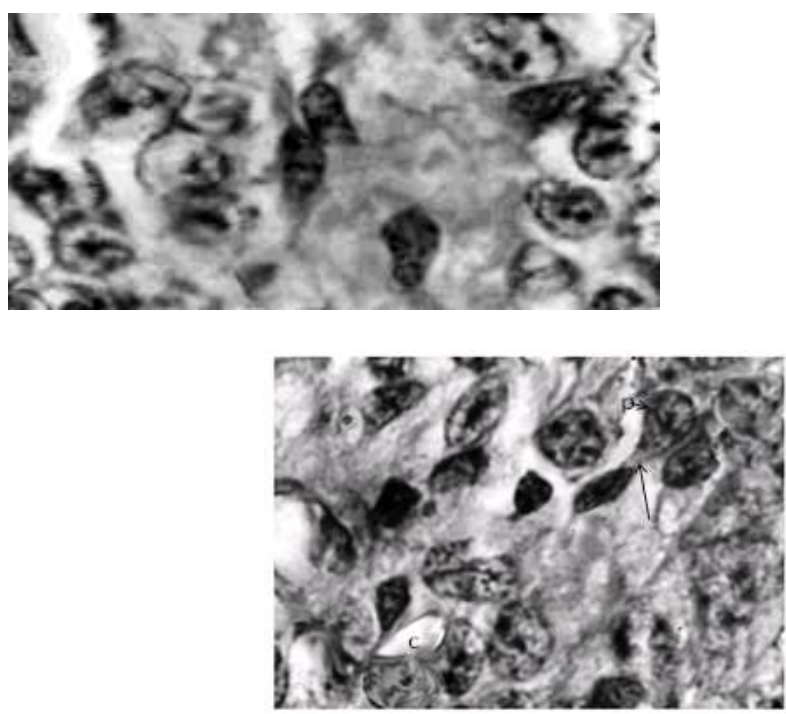

Fig 2. Darkly stained spindle shaped

Interstitial cells (arrow) in the gland Weil's stain counter stained with cresyl violet X1600

\section{Fig.3. Contacts between}

the interstial cells (arrow)and pinealocytes $p$, and blood capillaries bc. Weil's stain counter stain with cresyl violet $\mathrm{X} 1600$

Dense collections normally called acervulei or brain sand were found within the parenchyma of the gland of larger animals. There were two types of acervulei; the first ones, type I, consisted of concentric rings formed around a dark condensed nucleus (Fig. 4).

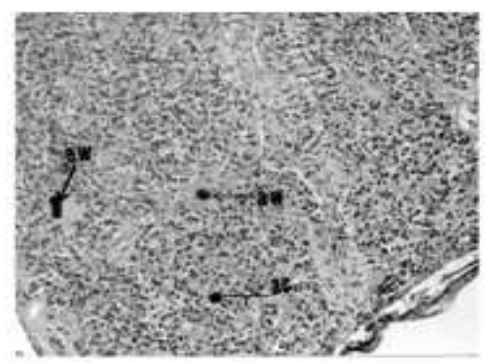

- Fig 4. Two types of acervuli in the pineal gland. aw, comprising of superimposed mucoid collections with cell free surrounding areas and ac, comprising of collections of concentric whorls with normal population of pinealocytes around it. Weil's stain counter stain with cresyl violet $\times 250$

The pinealocytes around such acervulei appeared to be normal in size and density. The other type II acervulei consisted of superimposed mucoid like droplets. The parenchyma around such acervulei was mostly cell - free. Some pyknotic cells were also found in its vicinity (Fig 4). At sites large darkly stained cells with condensed nuclei were seen making collections (Fig 5). 


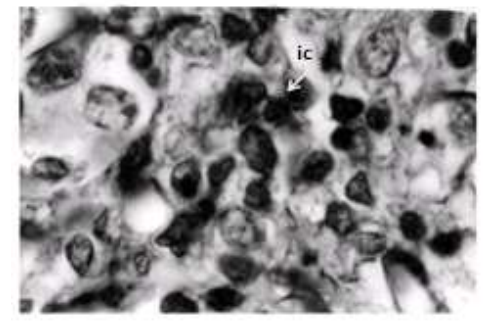

- Fig. 5 Collection of pyknotic nuclei ic. Red Holzer's stain X1600

Stages of formation of acervulei of the first type could be seen at places as concentric rings of dark and light zones (Fig. 6 and 7). Nerve fibers (fig. 8) and cell processes (fig 9) were seen encircling capillaries

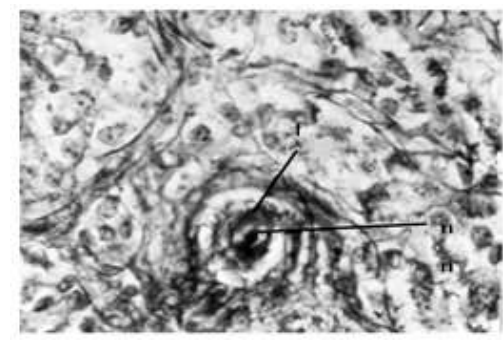

- Fig. 6. Formation of type 1 acervulus, interstial cell fibers $f$, encircling a central dark nucleus $n$,. Red Holzer's stain $\times 650$.

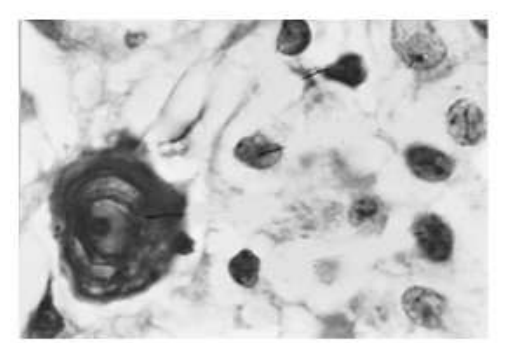

- Fig.7. Brain sand formed of concentric whorls type 1 . Weil's stain counter stain with cresyl violet $\times 5000$

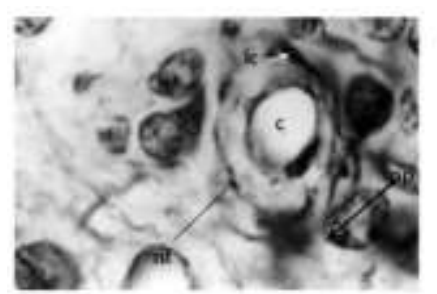

- Fig 8. Nerve fibers nf, and processes of pinealocytes pp,and interstial cells ic, around a capillary c. Red Holzer's stain X2000

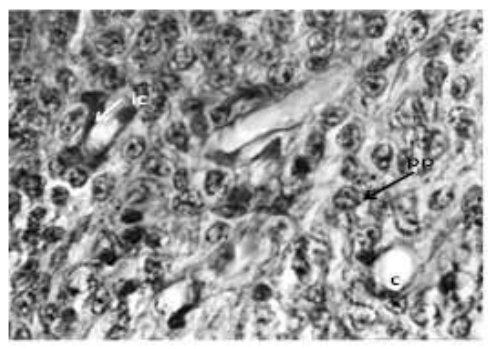

- Fig 9. Processes of pinealocytes pp, and interstial cells ic, around a capillary c. Weil's stain counter stained with cresyl violet (X 400)

After ganglionectomy the pinealocytes started degenerating and appeared like pyknotic nuclei. Many cell free areas were evident. In such areas a few neurons were seen (Fig. 10).

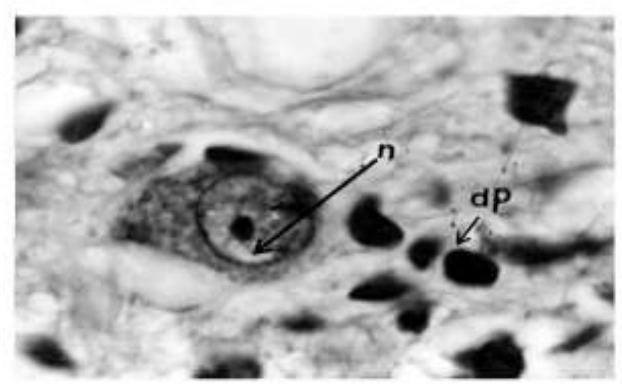

- Fig10. A neuron $n$, exposed after the degeneration of pineocytes dp, from group III. Weil's stain counter stain with cresyl violet X 1600 


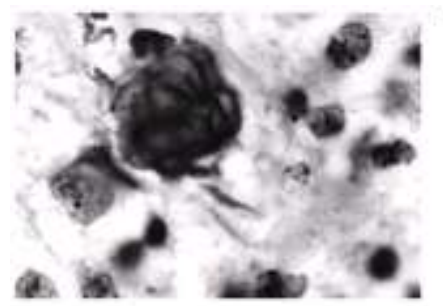

- Fig. 11 Acervulus of superimposed droplet types. Note the pycnotic pinealocytes in its neighbourhood. Weil's stain counter stained with cresyl violet (X 5000)

These areas were found close to acervulei of superimposed droplet types (Fig.11).

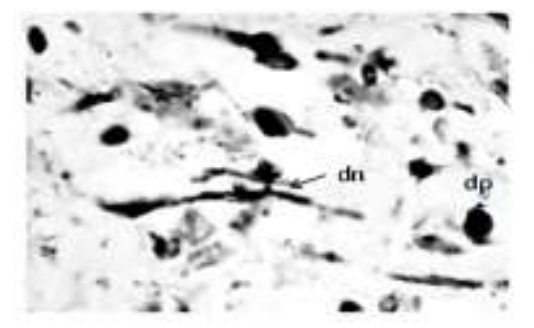

Fig 12 Degenerating nerve fibers dn, and pyknotic cells dp from the gland in group II. Glee's stain ( $\times 2500)$

- Fig 13: Cell free area cf,

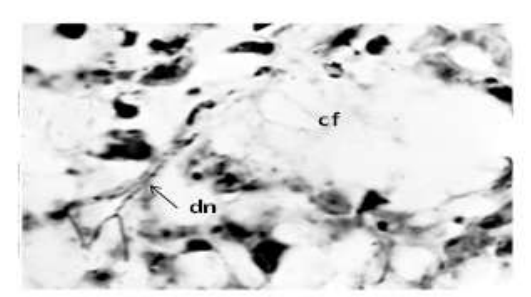
and degenerating nerve fibers dn in group III gland. Glee's stain (X 2500)

Many degenerating nerve fibers were seen in such glands (Fig. 12, \& 13). Darkly stained cells appearing to be pycnotic were found amidst the degenerating nerve fibers. The degenerating nerve fibers were seen on both sides even in group II. Most cells of Group III after 21 days of operation showed degenerated pinealocytes and cell free areas and a large acervulus of superimposed mucoid droplets at the apical part of the gland.

\section{Discussion:}

The infolding in the nuclear membrane of the pinealocytes is a known characteristic of these cells. No other cell is known to have infoldings in the nuclear membrane. Their presence in the pinealocytes is difficult to explain in this study. The interstitial cells are similar to those described by [8] in man. The interstitial cells and pinealocytes seem to be exchanging substances as seen by their contact with each other similar to glial cell. Degeneration of nerves after ganglionectomy was similar to that observed in smaller animals by [9, 10, 11, and 12]. The processes of the pinealocytes and interstitial cells are seen discharging into the capillaries in a typical endocrine manner similar to that found in glial cells.

After superior cervical ganglionectomy the nuclei of the pinealocytes are seen to become heterochromatic probably because of degeneration resulting from loss of function due to absence of light source. These findings seem to be similar to the findings reported in an ultra structural study of the changes in the cotton rat pineal gland after the sympathetic denervation by bilateral excision or decentralization of superior cervical ganglia. It was reported in this study and by [12] that the surface occupied by pineal parenchymal cells decreased and the profile areas of the cytoplasm, nucleus and nucleolus of the pinealocytes were also diminished. Cytoplasmic lipid droplets in the pinealocytes were markedly decreased in number and size in experimental rats. They concluded that rats treated by superior cervical ganglionectomy or decentralization showed morphological changes indicating a hypo functional pineal gland; there is no mention of acervulei formation in the rat pineal in this study

Superior cervical ganglionectomy results in the loss of pineal concretions in the adult male gerbil [11]. Collection of secretions in the form of superimposed mucoid type II secretions suggest that the removal of secretions from the gland is under the sympathetic control. Deprivation of sympathetic innervation leads in Djungarian hamsters not only to suppression of melatonin synthesis and secretions but, as appears from our studies, induces also morphological changes suggesting lower metabolic and secretary activity of pinealocytes Conclusion: The pineal gland of monkey is under autonomic nervous system control like most glands in the body. Accumulation of degenerated cells in the gland due to loss of activity leads to collections of the debris, which may be mistaken for brain sand or acervulei Type II. 
Acknowledgement: I wish to acknowledge the guidance offered to me in carrying out this work by my teachers Late Professor N.H. Keswani and Professor V. Bijlani both ex heads of the department of Anatomy All India Institute of Medical Sciences New Delhi India.

\section{References:}

[1] Descartes, Rene, "Medical Theorists A short history of medicine" by Singers, Charles and S. Ashworth Underworth, Oxford, Clarendon Press, pp 130-140, 1962.

[2] Kappers J. Ariens, "The pineal organ, An introduction" A Ciba foundation Symposium edited by G.E.W. Wolstenholme and Julia Knight, Churchill Livingstone, Edinburgh and London. 1971

[3] Solomon H., Snyder, Julius Axelrod, Richard J., Wurtman and Josef E. Fischer," Control of 5-hydroxytryptophan decarboxylase activity in the rat pineal gland by sympathetic nerves", The journal of pharmacology and experimental therapeutics. Vol. 147 , No. 3. pp 371-375,1965

[4] McNulty JA, Fox L, Taylor D, Miller M, Takaoka Y," Synaptic ribbon populations in the pineal gland of the rhesus monkey (Macaca mulatta)," Cell Tissue Res. 243(2),353-7, 1986

[5] Pansiri Phansuwan-Pujito, Morten Møller,Piyarat Govitrapong, "Cholinergic innervation and function in the mammalian pineal gland," Microscopy Research and Technique Special Issue: Mammalian Pineal Innervation, Volume 46, Issue 4-5, pages 281-295, 15 August - 1 September 1999

[6] Stefan Reuss , "Trigeminal innervation of the mammalian pineal gland and substance P in the pineal gland ," Microscopy Research and Technique,305-309, 1999

[7] Michael N. Sheridan and John R. Sladek, Jr., "Histofluorescence and Ultrastructural Analysis of Hamster and Monkey Pineal ," Cell and Tissue Research, Volume 164, Issue 2, pp 145-152, December 1975

[8] Tapp JE, Huxley M.," The histological appearance of the human pineal gland from puberty to old age.” J. Pathol ,108:137-144, 1972

[9] Lingappa JR, Zigmond RE.," A histochemical study of the adrenergic innervation of the rat pineal gland: evidence for overlap of the innervation from the two superior cervical ganglia and for sprouting following unilateral denervation,” J Pineal Res. 8(1),1-10. 1990.

[10] Calvo JL, Boya J, García-Mauriño JE., “ Ultrastructural changes in the rat pineal gland after sympathetic denervation. Quantitative study.” Neuroscience.21(3):893-902, Jun 1987.

[11] Champney TH, Joshi BN, Vaughan MK, Reiter RJ., "Superior cervical ganglionectomy results in the loss of pineal concretions in the adult male gerbil (Meriones unguiculatus)," The Anatomical Record Volume 211, Issue 4, pages 465-468, April 1985 